ORIGINAL ARTICLE

\title{
Loss of heterozygosity of the BRCA1 and FHIT genes in patients with sporadic breast cancer from Southern Brazil
}

\author{
S C L Santos, L R Cavalli, I J Cavalli, R S Lima, B R Haddad, E M S F Ribeiro
}

J Clin Pathol 2004;57:374-377. doi: 10.1136/jcp.2003.013490

See end of article for authors' affiliations ....................

Correspondence to: Dr B R Haddad, Institute for Molecular and Human Genetics, Georgetown University Medical Center 3800 Reservoir Road NW, Main 4000, Washington DC 20007, USA; haddadb1@ georgetown.edu

Accepted for publication 19 November 2003

\begin{abstract}
Aim: The evaluation of allelic losses at the FHIT and the BRCA1 genes and at three other loci at the $17 q$ region in a series of 34 sporadic breast cancer cases from Southern Brazil.

Methods: The samples were evaluated for loss of heterozygosity $(\mathrm{LOH})$ at the FHIT and the BRCA1 genes and at three other microsatellite markers at $17 q$, and the findings were correlated with clinicopathological parameters.

Results: The BRCA1 intragenic marker, D17S855, had the highest frequency of LOH, detected in 10 of 24 informative cases, followed by the D17S579 (six of 23 informative cases), D17S806 (five of 21 informative cases), and D17S785 markers (five of 21 informative cases). LOH at the FHIT intragenic marker, D3S1300, was found in six of 25 informative cases. In four of the six cases with LOH of the FHIT gene, there was concomitant loss of the BRCA1 intragenic marker.

Conclusions: The frequency of allelic losses in the FHIT and BRCA1 loci in the Southern Brazilian population is similar to that described in the general population. No correlations were found when the total LOH frequency was compared with tumour size, grade, or presence of axillary lymph node metastasis. Further studies using larger sporadic breast cancer samples and additional markers would be useful to confirm these findings, in addition to establishing more specific associations with clinicopathological parameters in this specific population.
\end{abstract}

B reast cancer is the most common malignancy in women and one in eight Brazilian women will probably develop breast cancer in their lifetime. ${ }^{1}$ Among the genetic alterations involved in the development and progression of breast cancer, allelic losses at particular chromosomal regions are common, and may indicate deletion of tumor suppressor genes. ${ }^{2}$

Loss of heterozygosity $(\mathrm{LOH})$ at $17 \mathrm{q}$ has been reported in about $30-60 \%$ of sporadic breast cancer cases and in many studies involves the BRCAl gene located at $17 \mathrm{q} 21$. . $^{3-5}$ However, in sporadic breast cancer, somatic mutations inactivating the BRCAl gene are rare, ${ }^{6}$ and it has been suggested that epigenetic mechanisms of inactivation, in addition to $\mathrm{LOH}$ at this locus, may take place. ${ }^{57}$

"Among the genetic alterations involved in the development and progression of breast cancer, allelic losses at particular chromosomal regions are common, and may indicate deletion of tumor suppressor genes"

The region 3pl4, where the FHIT gene is located, is a common site for chromosomal rearrangements in breast cancer, ${ }^{8}$ and contains the most active common fragile site in the human genome, the FRA3B locus. ${ }^{9}$ Genetic alterations with reduced expression of this gene are found in about $30 \%$ of breast cancers. ${ }^{10-12} \mathrm{LOH}$ studies have shown allelic losses at 3 pl4 in about $25 \%$ of primary breast carcinomas, suggesting that FHIT may have suppressor-like properties. ${ }^{10}{ }^{13}$ In familial breast cancer kindreds, early studies ${ }^{14}$ demonstrated a higher frequency of allelic imbalance at 3p14 compared with that seen in the sporadic breast cancers. More recent studies in BRCA2 positive tumours have shown a high frequency of FHIT LOH and reduced expression of the FHIT protein. ${ }^{12}$

In our study, we evaluated LOH at the BRCAl and FHIT loci, in addition to three other loci on $17 \mathrm{q}$, in a series of 34 sporadic breast cancer cases from Southern Brazil. The findings were analysed in relation to clinicopathological parameters

\section{MATERIALS AND METHODS \\ Samples}

Primary tumour and peripheral blood specimens were obtained from 34 patients undergoing surgery for sporadic breast cancer at the Hospital Nossa Senhora das Graças and Hospital de Clinicas, Curitiba, Southern Brazil, with informed consent. The patients had no family history of breast cancer and the mean (SD) age was 54.4 (12.5) years. The tumours were classified as grade 2 (17 samples) and grade 3 (17 samples) invasive ductal carcinomas. Table 1 presents the clinicopathological information of the patients.

\section{PCR amplification/LOH analysis}

DNA from matched normal and tumour tissues was amplified by the polymerase chain reaction (PCR) using five microsatellite markers with dinucleotide repeats. The following markers were used: D3S1300, intragenic to FHIT on 3p14.2; D17S855, intragenic to BRCAl on 17q21.2; D17S579 and D17S806 on 17q21.3; and D17S785 on 17q24. The markers were chosen based on their reported high heterozygosity rate. ${ }^{15}$ The forward primer for each set was labelled with either of two fluorescent dyes: HEX or FAM (Applied Biosystems/PE Biosystems, Foster City, California, USA).

In all cases, the markers were initially evaluated in the DNA from lymphocytes and the informative markers were studied in the tumour tissue. PCR was performed as described previously, ${ }^{16}$ using $20 \mathrm{ng} / \mathrm{\mu l}$ of genomic DNA, $100 \mathrm{mM}$ Tris/ $\mathrm{HCl}, 500 \mathrm{mM} \mathrm{KCl}, 480 \mathrm{nM}$ forward primer and $480 \mathrm{nM}$ reverse primer, $200 \mu \mathrm{M}$ dNTPs, and 0.5 unit of Taq polymerase in a total volume of $10 \mu \mathrm{l}$. Reactions were cycled as follows: $95^{\circ} \mathrm{C}$ for five minutes, then 35 cycles of $94^{\circ} \mathrm{C}$ for 15

Abbreviations: $\mathrm{LOH}$, loss of heterozygosity; PCR, polymerase chain reaction 
Table 1 Clinicopathological information and $\mathrm{LOH}$ analysis results

\begin{tabular}{|c|c|c|c|c|c|c|c|c|c|}
\hline Sample & $\begin{array}{l}\text { Histological } \\
\text { grade }\end{array}$ & $\begin{array}{l}\text { Tumour } \\
\text { size }(\mathrm{cm})\end{array}$ & Age (years) & $\begin{array}{l}\text { Lymph node } \\
\text { metastasis }\end{array}$ & D17S855 & D17S579 & D17S806 & D17S579 & D3S1300 \\
\hline CP 147 & IDC grade 2 & 4.0 & 35 & + & $\mathrm{LOH}$ & No LOH & No LOH & No LOH & $\mathrm{NI}$ \\
\hline CP 149 & IDC grade 2 & 2.0 & 60 & + & No $\mathrm{LOH}$ & $\mathrm{NI}$ & No LOH & No LOH & $\mathrm{NI}$ \\
\hline CP 158 & IDC grade 2 & 2.3 & 64 & + & $\mathrm{NI}$ & No LOH & $\mathrm{NI}$ & No LOH & No LOH \\
\hline CP 161 & IDC grade 2 & 2.5 & 54 & + & No LOH & No LOH & No LOH & No LOH & $\mathrm{NI}$ \\
\hline CP 165 & IDC grade 2 & 2.0 & 38 & + & No $\mathrm{LOH}$ & No LOH & No LOH & No LOH & No LOH \\
\hline CP 169 & IDC grade 2 & 1.0 & 53 & Unknown & $\mathrm{LOH}$ & $\mathrm{NI}$ & No LOH & No LOH & No LOH \\
\hline CP 176 & IDC grade 2 & 1.0 & 65 & - & $\mathrm{LOH}$ & $\mathrm{NI}$ & $\mathrm{LOH}$ & $\mathrm{LOH}$ & $\mathrm{LOH}$ \\
\hline CP 213 & IDC grade 2 & 2.5 & 58 & - & $\mathrm{NI}$ & $\mathrm{NI}$ & No LOH & No LOH & $\mathrm{NI}$ \\
\hline CP 227 & IDC grade 2 & 1.0 & 71 & Unknown & $\mathrm{NI}$ & No LOH & $\mathrm{NI}$ & $\mathrm{NI}$ & No LOH \\
\hline CP 228 & IDC grade 2 & 1.2 & 44 & - & No LOH & $\mathrm{NI}$ & No LOH & No LOH & $\mathrm{NI}$ \\
\hline CP 229 & IDC grade 2 & 2.0 & 78 & - & No LOH & $\mathrm{NI}$ & $\mathrm{NI}$ & No $\mathrm{LOH}$ & $\mathrm{NI}$ \\
\hline CP 231 & IDC grade 2 & 2.0 & 54 & + & $\mathrm{LOH}$ & No LOH & $\mathrm{NI}$ & $\mathrm{LOH}$ & $\mathrm{No} \mathrm{LOH}$ \\
\hline CP 239 & IDC grade 2 & 3.2 & 48 & - & $\mathrm{LOH}$ & $\mathrm{LOH}$ & $\mathrm{NI}$ & $\mathrm{NI}$ & $\mathrm{LOH}$ \\
\hline CP 253 & IDC grade 2 & 3.0 & 45 & + & $\mathrm{NI}$ & $\mathrm{LOH}$ & $\mathrm{LOH}$ & $\mathrm{NI}$ & No LOH \\
\hline CP 255 & IDC grade 2 & 2.0 & 59 & + & $\mathrm{NI}$ & No LOH & No LOH & No LOH & $\mathrm{No} \mathrm{LOH}$ \\
\hline CP 257 & IDC grade 2 & 1.7 & 46 & - & No LOH & No LOH & No LOH & $\mathrm{NI}$ & No LOH \\
\hline CP 271 & IDC grade 2 & 4.5 & 47 & + & No LOH & No LOH & No LOH & $\mathrm{NI}$ & No LOH \\
\hline HC 102 & IDC grade 3 & 4.0 & 55 & + & $\mathrm{NI}$ & No LOH & $\mathrm{NI}$ & $\mathrm{NI}$ & No LOH \\
\hline HC 146 & IDC grade 3 & 2.2 & 44 & Unknown & $\mathrm{NI}$ & $\mathrm{LOH}$ & $\mathrm{NI}$ & $\mathrm{LOH}$ & $\mathrm{NI}$ \\
\hline HC 167 & IDC grade 3 & 3.0 & 45 & + & $\mathrm{LOH}$ & No LOH & $\mathrm{NI}$ & No $\mathrm{LOH}$ & $\mathrm{LOH}$ \\
\hline CP 010 & IDC grade 3 & 2.0 & 65 & + & $\mathrm{No} \mathrm{LOH}$ & $\mathrm{LOH}$ & No LOH & $\mathrm{No} \mathrm{LOH}$ & No $\mathrm{LOH}$ \\
\hline CP 160 & IDC grade 3 & 2.8 & 54 & - & No LOH & No LOH & $\mathrm{NI}$ & $\mathrm{NI}$ & No LOH \\
\hline CP 183 & IDC grade 3 & 1.5 & 44 & Unknown & $\mathrm{NI}$ & $\mathrm{NI}$ & No $\mathrm{LOH}$ & $\mathrm{NI}$ & No LOH \\
\hline CP 212 & IDC grade 3 & 3.5 & 75 & + & No LOH & $\mathrm{NI}$ & $\mathrm{NI}$ & No $\mathrm{LOH}$ & No LOH \\
\hline CP 224 & IDC grade 3 & 4.0 & 76 & + & No LOH & No LOH & $\mathrm{LOH}$ & $\mathrm{NI}$ & $\mathrm{LOH}$ \\
\hline CP 243 & IDC grade 3 & 4.5 & 48 & + & $\mathrm{LOH}$ & No LOH & No $\mathrm{LOH}$ & $\mathrm{NI}$ & $\mathrm{NI}$ \\
\hline CP 248 & IDC grade 3 & 4.0 & 47 & Unknown & $\mathrm{NI}$ & $\mathrm{LOH}$ & No $\mathrm{LOH}$ & No $\mathrm{LOH}$ & No LOH \\
\hline CP 252 & IDC grade 3 & 2.8 & 90 & + & $\mathrm{NI}$ & No LOH & $\mathrm{LOH}$ & $\mathrm{NI}$ & $\mathrm{LOH}$ \\
\hline CP 275 & IDC grade 3 & 5.2 & 45 & + & $\mathrm{LOH}$ & $\mathrm{NI}$ & $\mathrm{NI}$ & $\mathrm{LOH}$ & No LOH \\
\hline CP 310 & IDC grade 3 & 1.7 & 53 & + & $\mathrm{LOH}$ & No LOH & No $\mathrm{LOH}$ & $\mathrm{NI}$ & $\mathrm{LOH}$ \\
\hline CP 313 & IDC grade 3 & 5.5 & 49 & + & No LOH & $\mathrm{NI}$ & No $\mathrm{LOH}$ & $\mathrm{NI}$ & $\mathrm{No} \mathrm{LOH}$ \\
\hline CP 330 & IDC grade 3 & 2.0 & 43 & - & $\mathrm{LOH}$ & $\mathrm{LOH}$ & $\mathrm{LOH}$ & $\mathrm{LOH}$ & No LOH \\
\hline CP 331 & IDC grade 3 & 4.2 & 55 & + & No LOH & No LOH & $\mathrm{NI}$ & No $\mathrm{LOH}$ & No LOH \\
\hline CP 338 & IDC grade 3 & 3.5 & 42 & - & No $\mathrm{LOH}$ & $\mathrm{NI}$ & $\mathrm{NI}$ & No $\mathrm{LOH}$ & $\mathrm{NI}$ \\
\hline
\end{tabular}

seconds, $55^{\circ} \mathrm{C}$ for 15 seconds, and $72^{\circ} \mathrm{C}$ for 30 seconds, followed by final elongation at $72^{\circ} \mathrm{C}$ for 10 minutes.

Allele sizes were determined by electrophoresis of PCR products in $6 \%$ denaturing polyacrylamide gels and compared with ROX 500 size standards (Applied Biosystems), using an automated sequencer (ABI 377). The fluorescent signals from the alleles with different sizes were recorded and analysed using GENOTYPER version 2.1 and GENESCAN version 3.1 software (Applied Biosystems). After visual examination of computer printouts (by two independent observers), LOH was determined mathematically according to the Genotyper User Manual (Applied Biosystems).

\section{Statistical analysis}

Significance was determined using $\chi^{2}$ and $t$ tests to evaluate whether LOH frequency at specific loci was equally distributed among the clinicopathological parameters; $p$ values $<0.05$ were considered significant.

\section{RESULTS}

Specimens from 34 patients with sporadic invasive ductal carcinoma were assessed for LOH at the FHIT and the BRCAl loci and at three other markers on 17q. Table l summarises the results. The BRCAl intragenic marker, D17S855, showed the highest frequency of LOH (10 of 24 informative cases), followed by the D17S579 (six of 23 informative cases), D17S806 (five of 21 informative cases), and D17S785 markers (five of 21 informative cases). LOH at the FHIT intragenic marker, D3S1300, was found in six of 25 informative cases. Four of these six cases also had loss of the Dl7S855 marker. Figure 1 shows examples of losses at the BRCAl and FHIT genes and at the Dl7S785 marker. There was no significant difference in the distribution of frequencies of samples that were non-informative, positive, or negative for $\mathrm{LOH}$ among the five microsatellite markers $\left(\chi_{8}^{2}=4.64 ; \mathrm{p}>0.70\right)$.

\section{Clinicopathological associations}

In this study, tumours with $\mathrm{LOH}$ were equally distributed among the histopathological grade $2\left(\chi^{2}{ }_{8}=3.67 ; \mathrm{p}>0.80\right)$ and $3\left(\chi_{8}^{2}=5.44 ; p>0.70\right)$ specimens. In addition, no significant difference was found when the $\mathrm{LOH}$ frequencies were compared for tumour size $(\leqslant 2.8 \mathrm{~cm}$ and $>2.8 \mathrm{~cm}$; $\left.\chi_{1}^{2}=0.36 ; p>0.50\right)$. However, when the tumour size was compared between tumours of distinct grades, it was found that grade 3 tumours were larger than grade 2 (mean (SD), $3.32(1.17) v 2.23(0.97) \mathrm{cm})$. This difference was significant using the $t$ test $\left(\mathrm{t}_{16}=2.87 ; \mathrm{p}<0.05\right)$.

Women who were $\leqslant 50$ years of age presented with larger tumours than women $\geqslant 50$ years $\left(\chi^{2}{ }_{1}=5.67 ; p<0.05\right)$. As expected, there was no difference when the age of the patients was compared with tumour grades $\left(\chi^{2}{ }_{1}==0.47\right.$; $\mathrm{p}>0.30$ ) or the presence of metastasis in the axillary lymph nodes $\left(\chi_{1}^{2}=0.65 ; p>0.30\right)$. Tumours from patients who presented with metastasis in the axillary lymph nodes did not show an increased frequency of $\mathrm{LOH}$ when compared with those without metastasis $\left(\chi^{2}=2.44 ; \mathrm{p}>0.10\right)$.

\section{DISCUSSION}

Extensive searches for somatic mutations in the BRCAl gene at $17 \mathrm{q} 21$ have revealed that such mutations are rare in nonfamilial breast and ovarian cancer, despite the high incidence of LOH at the BRCAl locus seen in these tumours. ${ }^{6}$ Studies have suggested that loci surrounding the BRCAl gene may be the major targets in $17 \mathrm{q}$ deletions. ${ }^{17}$

Frequent deletions in breast cancer are found on chromosome arm $3 p$, mainly at $3 p 14.2$, where the FHIT gene is located, ${ }^{10-12}$ which can lead to LOH at this gene locus. High 
Marker D17S855

Marker D3S 1300

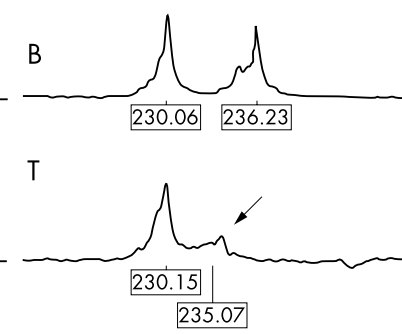

frequencies of $\mathrm{LOH}$, abnormal transcripts, and reduced expression of the FHIT protein have been observed in invasive breast carcinomas, in addition to some benign breast diseases, suggesting that FHIT alterations are early events in mammary tumorigenesis. ${ }^{11} 1819$

In our study, we have assessed LOH at 3pl4 (FHIT gene) and three regions of chromosome 17q (17q21.2 (BRCAl gene), 17q21.3, and 17q24) in patients with sporadic breast cancer. The highest incidence of $\mathrm{LOH}(42 \%)$ was found for the marker D17S855, intragenic to the BRCAl gene. This finding is in agreement with other studies, ${ }^{5}{ }^{15} 20$ supporting the hypothesis that the BRCAl gene plays an important role in sporadic breast cancer. No significant difference was found for marker D17S855 between grade 2 and grade 3 tumours, suggesting that deletions in the BRCAl gene probably occur early in mammary carcinogenesis. This result contrasts with data previously reported showing an association between LOH in BRCAl and grade 3 tumours. ${ }^{21}$

Similar frequencies of LOH for markers D17S579 and D17S806 were found in other studies in sporadic breast cancer cases. ${ }^{15}$ The frequencies of $\mathrm{LOH}$ observed in this and other reports suggest the presence of other tumour suppressor genes at these regions that may participate in sporadic mammary tumorigenesis. However, we cannot rule out the possibility that the allelic losses in these regions may be a result of partial or total loss of chromosome 17, which is a common cytogenetic abnormality in breast cancer cases.

$\mathrm{LOH}$ for the marker D3S1300, intragenic to FHIT, has been reported to occur in frequencies ranging from $24 \%$ to $59 \%$ in breast cancer. ${ }^{10}{ }^{13} 22$ In our study, we detected $\mathrm{LOH}$ at this marker in $24 \%$ of cases. Of interest was our observation that four of six cases that showed losses for the D3S1300 marker also showed losses at the BRCAl marker, suggesting a possible association between allelic losses in these genes (table 1). It is possible that $\mathrm{LOH}$ at the BRCAl gene occurs as an early event, causing genetic instability and leading to allelic losses at the FHIT region. Additional studies in larger series of cases using intragenic markers at these genes are necessary to test this hypothesis. However, a correlation between the expression of these genes was noted at the protein level by Turner et al. ${ }^{23}$ These authors found that cases with mutations of the BRCAl gene also had reduced expression of the FHIT protein, suggesting the necessity of BRCAl integrity to protect cells from genetic instability at fragile loci, such as FRA3B, where the FHIT gene is located.

\section{"No significant difference was found for marker D17S855 between grade 2 and grade 3 tumours, suggesting that deletions in the BRCA1 gene probably occur early in mammary carcinogenesis"}

The frequency of total LOH observed in the analysis of our sporadic breast tumour cases was found to be equally distributed among the tumours classified as grade 2 and
Marker D17S785

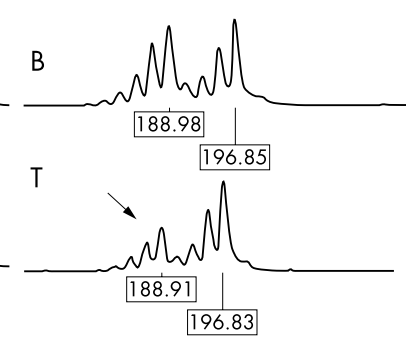

Figure 1 Examples of allelic losses (arrows) seen for the intragenic markers of the BRCAI and FHIT genes and for the marker D17S785. B, blood; T, tumour. grade 3. In addition, no significant difference was found when the LOH frequency was compared for tumour size $(\leqslant 2.8 \mathrm{~cm}$ and $>2.8 \mathrm{~cm})$. However, when tumour size was compared between the two grades of tumours, it was found that grade 3 tumours were larger than grade 2 tumours.

Our study revealed that women $\leqslant 50$ years of age presented with tumours of larger size than women $>50$ years, suggesting a faster tumour evolution in younger women. A higher frequency of $\mathrm{LOH}$ was also found in the younger group, although this observation did not reach significance by the $\chi^{2}$ test. Similar results were reported by Phelan and colleagues ${ }^{15}$ and Querzoli et al. ${ }^{24}$ Age and histopathological grades were not associated in this population, corroborating findings by Johnson et al. ${ }^{5}$ In addition, we found no increase of the total $\mathrm{LOH}$ frequency in grade 3 tumours compared with grade 2 tumours. Previous studies have reported that breast carcinoma in younger women $(<35$ years old $)$ usually presents with more aggressive pathological features, such as significantly higher proliferation rates, lack of steroid receptors, and a higher chance of having grade 3 tumours. ${ }^{25}$

In our cases, the tumours that presented with metastasis to the axillary lymph nodes did not have a higher frequency of LOH. This result is supported by other studies, ${ }^{15} 2226$ but contrary to the study of Regitnig et al, ${ }^{25}$ who found an association between a higher frequency of LOH at the 17S855 marker and lymph node metastasis in a series of 40 primary sporadic breast tumours and their locally recurrent breast carcinomas.

Although it is important to evaluate breast cancer cases from different ethnic groups to look for the possible presence of unusual changes associated with specific ethnicities, we found no such differences at the markers studied here. Further studies using larger sporadic breast cancer samples and additional markers would be useful to confirm our findings and to establish more specific associations with

\section{Take home messages}

- The frequency of allelic losses in the FHIT and BRCA1 loci in the Southern Brazilian population is similar to that described in the general population

- No correlations were found when the total loss of heterozygosity frequency was compared with tumour size, grade, or presence of axillary lymph node metastasis

- Further studies using larger sporadic breast cancer samples and additional markers would be useful to confirm these findings, and to establish more specific associations with clinicopathological parameters in our patients 
clinicopathological parameters in our specific population of patients from Southern Brazil.

\section{ACKNOWLEDGEMENTS}

This work was partially supported by a research grant from CNPq (Conselho Nacional de Desenvolvimento Científico e Tecnológico, Brazil). SSL was supported by a scholarship from CAPES (Coordenação de Aperfeiçoamento de Pessoal de Ensino Superior, Brazil).

\section{Authors' affiliations}

S C L Santos, I J Cavalli, E M S F Ribeiro, Departamento de Genética, Universidade Federal do Parana, Curitiba, PR, 81531-970 Brazil

L R Cavalli, B R Haddad, Institute for Molecular and Human Genetics, Lombardi Comprehensive Cancer Center, Georgetown University Medical Center, Washington, DC 20007, USA

R S Lima, Departamento de Oncologia, Hospital Nossa Senhora das Graças, Curitiba, PR, 80810-120 Brazil

\section{REFERENCES}

1 Ministério da Saúde. Instituto Nacional do Câncer (available at http:// www.inca.gov.br). Last accessed on December 19, 2002

2 Callahan R, Campbell G. Mutations in human breast cancer: an overview. J Natl Cancer Inst 1989:81:1780-6.

3 Beckmann MW, Picard F, An HX, et al. Clinical impact of detection of loss of heterozygosity of BRCA1 and BRCA2 markers in sporadic breast cancer. Br J Cancer 1996;73:1220-6.

4 Hanby AM, Kelsell DP, Potts HW, et al. Association between loss of heterozygosity of BRCA1 and BRCA2 and morphological attributes of sporadic breast cancer. Int J Cancer 2000;88:204-8.

5 Johnson SM, Shaw JA, Walker RA. Sporadic breast cancer in young women: prevalence of loss of heterozygosity at p53, BRCA1 and BRCA2. Int J Cancer 2002;98:205-9.

6 Rosen EM, Fan S, Pestell RG, et al. BRCA1 gene in breast cancer. J Cell Physiol 2003; 196:19-41.

7 Van der Looij M, Cleton-Jansen AM, Van Eijk R, et al. A sporadic breast tumor with a somatically acquired complex genomic rearrangement in BRCA1. Genes Chromosomes Cancer 2000;27:295-302.

8 Petersson C, Pandis N, Mertens F, et al. Chromosome aberrations in prophylactic mastectomies from women belonging to breast cancer families. Genes Chromosomes Cancer 1996;16:185-8.

9 Glover TW, Stein CK. Chromosome breakage and recombination at fragile sites. Am J Hum Genet 1988;43:265-73.
10 Ahmadian M, Wistuba II, Fong KM, et al. Analysis of the FHIT gene and FRA3B region in sporadic breast cancer, preneoplastic lesions, and familial breast cancer probands. Cancer Res 1997;57:3664-8.

11 Campligio M, Pekarsky Y, Menard S, et al. FHIT loss of function in human primary breast cancer correlates with advanced stage of the disease. Cancer Res 1999;59:3866-9.

12 Gatalica Z, Lele SM, Rampy BA, et al. The expression of FHIT protein is related inversely to disease progression in patients with breast carcinomas. Cancer 2000;88:1378-83.

13 Ingvarsson S. FHIT alterations in breast cancer. Semin Cancer Biol 2001:11:361-6.

14 Bergthorsson JT, Eiriksdottir G, Barkardottir RB, et al. Linkage analysis and allelic imbalance in human breast cancer kindreds using microsatellite markers from the short arm of chromosome 3. Hum Genet 1995;96:437-43.

15 Phelan CM, Borg A, Cuny M, et al. Consortium study on 1280 breast carcinomas: allelic loss on chromosome 17 targets subregions associated with family history and clinical parameters. Cancer Res 1998;58:1004-12.

16 Cavalli LR, Singh B, Isaacs C, et al. Loss of heterozygosity in normal breast epithelial tissues and benign breast lesions in BRCA1/2 carriers with breast cancer. Cancer Genetics Cytogenetics 2004;149:38-43.

17 Sourvinos G, Kiaris H, Tsikkinis A, et al. Microsatellite instability and loss of heterozygosity in primary breast tumours. Tumor Biol 1997;18:157-66.

18 Hayashi S, Tanimoto K, Hajiro-Nakanishi K, et al. Abnormal FHIT transcripts in human breast carcinomas: a clinicopathological and epidemiological analysis of 61 Japanese cases. Cancer Res 1997;57:1981-5.

19 Bieche I, Latil A, Becette V, et al. Study of FHIT transcripts in normal and malignant breast tissue. Genes Chromosomes Cancer 1998;23:292-9.

20 Ando $\mathrm{Y}$, Iwase $\mathrm{H}$, Ichihara $\mathrm{S}$, et al. Loss of heterozygosity and microsatellite instability in ductal carcinoma in situ of the breast cancer. Cancer Lett 2000;156:207-14

21 Silva JM, Gonzalez R, Provencio M, et al. Loss of heterozygosity in BRCA and BRCA2 markers and high-grade malignancy in breast cancer. Breast Cancer Res Treat 1999;53:9-17

22 Maitra A, Wistuba II, Washington C, et al. High resolution chromosome 3p allelotyping of breast carcinomas and precursor lesions demonstrates frequent loss of heterozygosity and a discontinuous pattern of allele loss. Am J Pathol 2001;159:119-30

23 Turner BC, Ottey M, Zimonjic DB, et al. The fragile histidine triad/common chromosome fragile site $3 \mathrm{~B}$ locus and repair-deficient cancers. Cancer Res 2002;62:4054-60.

24 Querzoli P, Albonico G, Di Lasio MG, et al. Biophenotypes and survival of BRCA1 and TP53 deleted breast cancer in young women. Breast Cancer Res Treat $2001 ; 66: 135-42$

25 Regitnig $\mathbf{P}$, Moser R, Thalhammer $M$, et al. Microsatellite analysis of breast carcinoma and corresponding local recurrences. J Pathol 2002;198:190-7.

26 Takita K, Sato T, Miyagi M, et al. Correlation of loss of alleles on the short arms of chromosomes 11 and 17 with metastasis of primary breast cancer to lymph nodes. Cancer Res 1992;52:3914-17. 